\title{
THEORETICAL CALCULATIONS OF ECONOMIC LIFE OF FIREFIGHTING APPLIANCES BASED ON CHASSIS TATRA IN THE SOUTH MORAVAN REGION
}

This paper is focused on the evaluation of economic data obtained from operational records of firefighting equipment with a focus on firefighting and rescue appliances, especially on exit vehicles based on the chassis CAS 20 - TATRA T815-231R55 18 325 4x4.2. These vehicles have been operated by professional units of the Fire and Rescue Service in the South Moravian Region since September 2013. The producer of firefighting superstructures WISS GROUP, Bielsko-Biala, Poland, was a supplier of all these vehicles. The paper's aim is to specify the optimum lifetime of the firefighting vehicles by the analysis of firefighting vehicles' economical operation. Theoretical calculations of the optimum lifetime have been processed with implementing both the method of exponential trends and the Brown method. The residual value of vehicles has been calculated both according to the current Czech tax law, and to the Expert Standard Valuation of motor vehicles in force in the Czech Republic.

Keywords: acquisition value, costs, depreciation, residual value, economic life

\section{Introduction}

This paper follows on previous authors' publications focused on the assessment of economic data of firefighting appliances based on the chassis Renault Midlum and Mercedes-Benz Atego [1], [2]. These vehicles were deployed at professional units of the Fire and Rescue Service of the Zlin and Moravian-Silesian Region during the reporting period. This paper shows results of alternative calculations of theoretical economic lifetime of observed appliances. The comparison of results for all the assessed vehicles is performed in the conclusion.

\section{Characteristics of observed firefighting and rescue appliances}

Essential tactical-technical characteristics of the assessed appliances TATRA can be traced in the literature, e.g. [3], [4]. Key operational and economic characteristics of the monitored equipment for the period October 2013 to November 2016 are shown in the Table 1. All three vehicles were bought at the same time, with the purchase price CZK 5,626,467 (221,427.28 ). Those appliances started to operate on October 17, 2013. The primary operational data from the information system IKIS II were exported into Excel file and then used for the assessment of operation and maintenance costs of those vehicles [5].

\section{Methods}

Economic life of the vehicle can be generally characterized as reaching the limit state when further operation is economically unsustainable [6]. The economic efficiency of the investment is calculated to assess the economic life of the technical system in the business environment. This procedure would be relatively difficult to apply for the evaluation of firefighting appliances. The methodology of these calculations is based on the input data extremely difficult to define in the sphere of public service [7], [8]. One of the reasons for the impossibility of using this calculation method is the requirement of the initial setting of the technical system's lifetime. The approximate lifetime can be only theoretically estimated or assumed from the Machinery Service Order [9] in which approximate lifetimes of firefighting appliances are set. The 10 years long standard lifetime of the rescue firefighting vehicle is prolonged for next 6 years after technical improvement.

\footnotetext{
* ${ }^{1}$ Ladislav Janosik, ${ }^{2}$ Ivana Janosikova, ${ }^{1}$ Pavel Polednak

${ }^{1}$ Faculty of Safety Engineering, VSB - Technical University of Ostrava, Czech Republic

${ }^{2}$ Faculty of Economics, VSB - Technical University of Ostrava, Czech Republic

Email: ladislav.janosik@vsb.cz
} 
Table 1 Basic characteristics of referred vehicles during years 2013-2016

\begin{tabular}{|c|c|c|c|c|c|c|c|c|c|}
\hline \multirow[t]{2}{*}{$\begin{array}{l}\text { Vehicle } \\
\text { location }\end{array}$} & \multirow[t]{2}{*}{ Registration mark } & \multicolumn{2}{|c|}{ Year } & \multirow{2}{*}{$\begin{array}{c}\text { Mileage } \\
{[\mathrm{km}]}\end{array}$} & \multirow{2}{*}{$\begin{array}{c}\text { Amount of } \\
\text { fuel } \\
\text { [1] }\end{array}$} & \multicolumn{2}{|c|}{ Maintenance and repair costs } & \multicolumn{2}{|c|}{ Cumulative costs } \\
\hline & & & & & & {$[\mathrm{CZK}]$} & [EUR] & {$[\mathrm{CZK}]$} & [EUR] \\
\hline \multirow[t]{4}{*}{ Vyskov } & 5B4 3485 & 2013 & 0 & 3,218 & 1,722 & 0 & 0 & 0 & 0 \\
\hline & & 2014 & 1 & 5,269 & 3,061 & 7,074 & 278.39 & 7,074 & 278.39 \\
\hline & & 2015 & 2 & 10,149 & 4,756 & 23,414 & 921.45 & 30,488 & $1,199.84$ \\
\hline & & 2016 & 3 & 7,721 & 4,438 & 43,343 & $1,705.75$ & 73,831 & $2,905.59$ \\
\hline \multirow[t]{4}{*}{ Pozorice } & 5B4 3487 & 2013 & 0 & 2,800 & 1,614 & 0 & 0.00 & 0 & 0.00 \\
\hline & & 2014 & 1 & 4,050 & 2,846 & 0 & 0.00 & 0 & 0.00 \\
\hline & & 2015 & 2 & 8,526 & 6,231 & 45,898 & $1,806.28$ & 45,898 & $1,806.28$ \\
\hline & & 2016 & 3 & 5,819 & 4,259 & 24,019 & 945.24 & 69,916 & $2,751.52$ \\
\hline \multirow[t]{4}{*}{ Tisnov } & 5B4 3486 & 2013 & 0 & 3,198 & 1,493 & 0 & 0.00 & 0 & 0.00 \\
\hline & & 2014 & 1 & 8,508 & 4,827 & 17,721 & 697.39 & 17,721 & 697.39 \\
\hline & & 2015 & 2 & 9,716 & 5,347 & 41,965 & $1,651.51$ & 59,686 & $2,348.90$ \\
\hline & & 2016 & 3 & 8,153 & 4,731 & 24,019 & 945.24 & 83,704 & $3,294.14$ \\
\hline
\end{tabular}

Therefore, the calculation of the monitored vehicles' economic life was performed by use of the two simple and generally known methods, the exponential trends method and the Brown method [10], [11]. Calculations according to both methods were performed for a 4-year operation time period. The residual value of appliances, which is one of data used for calculations, was variously calculated according to the Act No. 586/1992 Coll on Income Taxes [12], and according to the Expert Standard No. I/2005 - Valuation of motor vehicles [13].

\subsection{The Exponential trend method}

Theoretical foundations of the method were published in 1963 [14]. The principle is displayed graphically in Figure 1.

This method is based on the theoretical assumption that the value of firefighting appliances in time $N_{p}(t)$ has the shape of downward sloping exponential curve [10]. The curve is defined by the equation:

$$
N_{p}(t)=C \cdot e^{-\alpha \cdot t}
$$

Similarly, one can define the trend of costs for maintenance and repairs $N_{u}(t)$ by using an upward sloping exponential curve according to the equation:

$$
N_{u}(t)=A \cdot e^{\beta \cdot t} .
$$

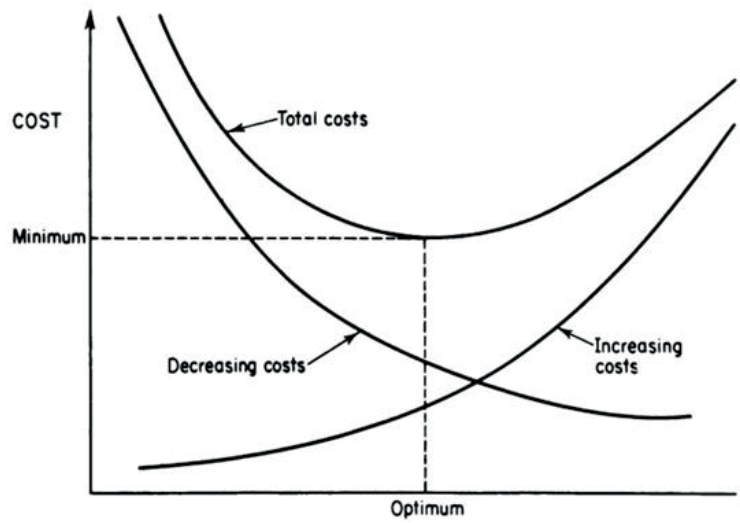

Figure 1 Fundamentals of operation research [14]

The total value of firefighting appliances $N_{c}(t)$ is a sum of Equation (1) and Equation (2):

$N_{c}(t)=C \cdot e^{-\alpha \cdot t}+A \cdot e^{\beta \cdot t}$.

Then, one calculates the local extreme of this function by modification of Equation (3). The local extreme $\left(N_{c}(t)\right.$ minimum in this case) represents the optimal time $T_{\text {opt }}$ for replacing the appliance:

$T_{o p t}=\frac{1}{\alpha+\beta} \cdot \ln \left(\frac{\alpha \cdot C}{\beta \cdot A}\right)$. 


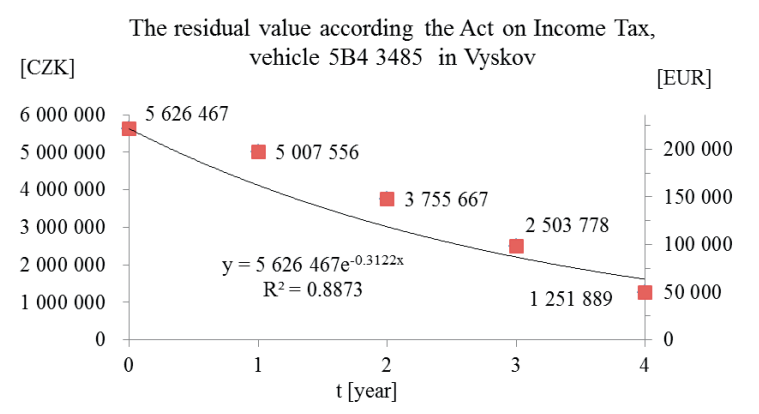

Figure 2 The residual value according to the Act on Income Tax

After reaching the minimum point, the function $N_{c}(t)$ rises, due to declining price of the firefighting vehicle $N_{p}(t)$ and increasing maintenance and repair costs $N_{u}(t)$. After processing the input economic data and building charts of the exponential curve (by using appropriate software, e.g. MS Excel), constants $A$, $C$ and exponent coefficients $\boldsymbol{\alpha}, \boldsymbol{\beta}$, were obtained.

\subsection{The Brown method}

This method was published first over 55 years ago in the journal Railway Age, in Brown's paper "What's the Life of a Diesel?" Theoretical foundations then were summarized and published in 1963 [14]. The method was used for the preliminary determination lifetime of rail vehicles [11]. The optimum lifetime $T_{\text {opt }}$ is given by:

$T_{\text {opt }}=\sqrt{\frac{2 \cdot H_{0}}{B}}$.

Here, $H_{0}$ is the vehicles' acquisition value given as a percentage $=100 \%$ and $B$ is the linear incremental trend coefficient of the maintenance and repair costs. This coefficient was obtained likewise from the charts using linear regression of data. Application of this method is connected with some weaknesses, as discussed below in the results.

\subsection{Vehicle's residual value calculations}

Calculations of the vehicle's residual value, according to the Act on Income Tax [12], consider the depreciation period of 5 years in Article 30 within motor vehicles for special purposes, according to the classification in Appendix No. 1 of the Act. Depreciation percentages are fixed for the first year at the level of $11 \%$ and they are changed to $22.25 \%$ for the next four years. Calculating the relative technical value of the vehicle PTHS in any year of operation is carried out in percentages of the purchase price, in accordance with the Expert Standard [13], by equation:

$P T H S=\frac{T H S N \cdot(100-Z A) \cdot(100 \pm T S) \cdot P D S}{10^{6}}$.

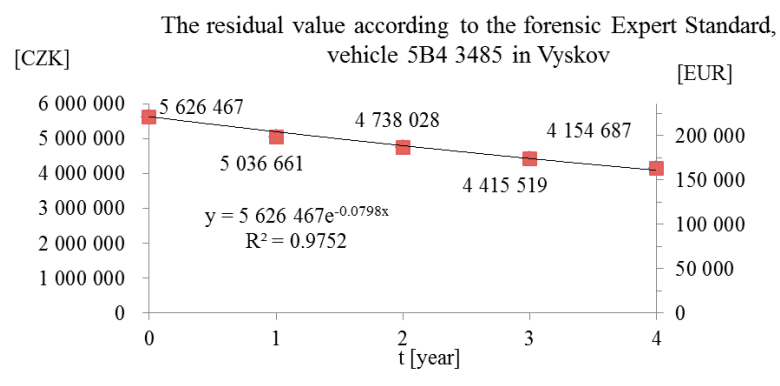

Figure 3 The residual value according to the forensic Expert Standard

The initial technical value of the group $T H S N=100 \%$, technical condition changes $T S=0.0 \%$ and the relative group proportion value $P D S=100 \%$ were applied in the equation, in the case of maintained and operational firefighting appliances. Basic amortization $Z A$ [\%] which is calculated as the arithmetic average of the following equation was the only variable in the Equation (6):

$Z A=\frac{Z A D+Z A P}{2}$.

The ZAD parameter is the basic percent reduction during the operation defined in Annex No. 1.4 of the Expert Standard [13] and ranges from $20 \%$ in the first year of operation to $90 \%$ in the tenth and following year of operation. The ZAP parameter [\%] determines the percentage of the basic reduction for the mileage (see ibid.).

\section{Results}

Overall results of calculations are stated in the following tables and graph exemplifications of which are evident constants and coefficients exponents values used for the calculations in Equation (4) and Equation (5).

A significant decrease in the residual value of all the observed vehicles was elicited by calculating according to the Act on Income Tax [12], as shown in Figure 2 on the case of the vehicle registration number 5B4 3485 from the fire station Vyskov. The difference in results of the residual value calculations according to the Expert Standard [13] is shown in Figure 3. It is evident that the Expert Standard is more suitable under consideration the mileage of the firefighting appliance. This can significantly affect the vehicle wearing. Finally, the Expert Standard gives the higher residual value of the particular vehicle at the end of the year 2016, which is closer to its market value.

Results of the repair cost functions calculations according to both the exponential trend method and the Brown method, can be seen in Figure 4 and Figure 5. Those results for all three vehicles are distorted by the fact that the vehicles are under warranty. Each vehicle has travelled an average of $3000 \mathrm{~km}$ in less than 


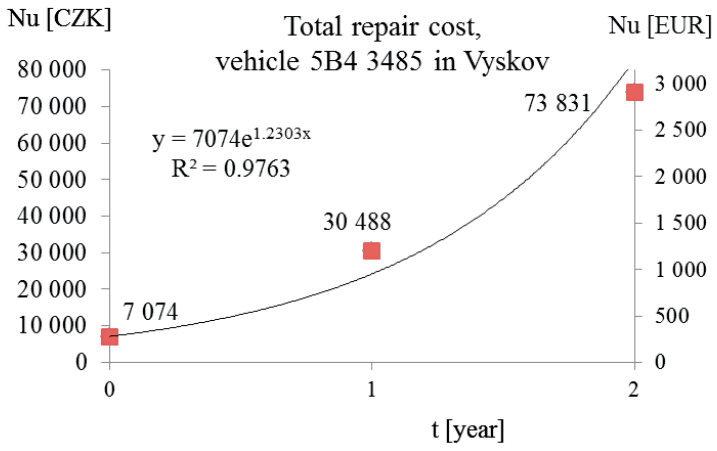

Figure 4 Total repair costs according to the exponential trends method
[\%] Total repair costs as a percentage of the

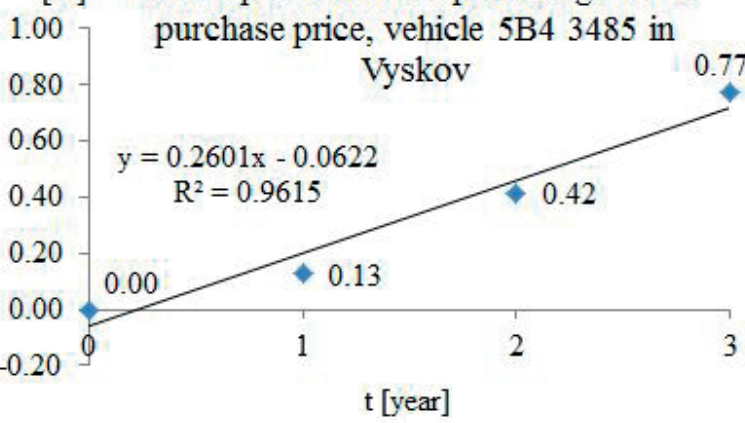

Figure 5 Repair costs according to the Brown method

Table 2 Economic lifetime in accordance with the Act on Income Tax

Maintenance and repairs cost ratio $N_{u}(t)$

Residual value of firefighting appliances in time $N_{p}(t)$ coefficients

\begin{tabular}{|c|c|c|c|c|c|c|c|c|}
\hline $\begin{array}{l}\text { Vehicle } \\
\text { location }\end{array}$ & $\begin{array}{l}\text { Registration } \\
\text { mark }\end{array}$ & $A[\mathrm{CZK}]$ & $\beta[-]$ & $\begin{array}{c}\text { Correlation } \\
\text { coefficient } R\end{array}$ & $C[\mathrm{CZK}]$ & $\alpha[-]$ & $\begin{array}{c}\text { Correlation } \\
\text { coefficient } R\end{array}$ & \\
\hline Vyskov & 5B4 3485 & 7,074 & 1.2303 & 0.99 & $5,626,467$ & 0.3122 & 0.94 & 3.4 \\
\hline Pozorice & 5B4 3487 & 45,898 & 0.4209 & 1.00 & $5,626,467$ & 0.3122 & 0.94 & 6.2 \\
\hline Tisnov & 5B4 3486 & 17,721 & 0.8639 & 0.94 & $5,626,467$ & 0.3122 & 0.94 & 4.0 \\
\hline
\end{tabular}

three months of use during the year 2013 and underwent the first servicing under warranty conditions, i.e. free of charge. In terms of the traffic load, an average number of the rescue exits per vehicle was only 16 , but there were 38 condition rides when the vehicle was not overloaded (in 2013). Hence, there was not much opportunity for the occurrence of a failure. From a mathematical point of view, this additionally means that the exponential curve, describing the development of maintenance and repair costs, begins since 2014, when these costs were non-zero.

Further distortions in the trend of maintenance and repair costs might be caused by vehicle accidents. The vehicle 5B4 3485 from Vyskov Station had two traffic accidents in 2014 and afterwards it was out of service for almost six months - from February 3 to May 22, when repair costs reached approximately CZK 268,000 (10,547.03 €), and then from August 9 to October 14 , when repair cost amount was approximately CZK 220,000 $(8,658.01 €)$. The operating load of that vehicle was about $5300 \mathrm{~km}$ in 2014. The vehicle 5B4 3487 from Pozorice Station had one traffic accident in the year 2014, and was out of operation from February 2 to May 5 (the repair cost increased to CZK 746,000 , that was $29,358.52 €$ ). The operating load of that vehicle was about $4000 \mathrm{~km}$ in 2014 . The recorded maintenance and repair costs are zero for this vehicle in 2014.

Depreciation results, according to the Act on Income Tax [12], are presented in Table 2. Table 3 displays variant calculations results while using depreciation according to the Expert Standard [13]. Both results were obtained by applying the exponential trend method. Compared to the previous calculations published in [1], [2], the impact of the residual value method had not such a significant effect on the resulting economic lifetime in the case of vehicles deployed at stations Vyskov and Pozorice.

Total maintenance and repair costs in particular years and B-coefficient values for the theoretic recovery time calculating are summarized in Table 4. Figure 5 shows the linear trend of the cumulative cost. Both the curve, and its mathematical expression with the B-coefficient used for the calculation according to Equation (5) were automatically generated by the MS Excel.

Results acquired by the Brown method with using the linear trends are shown in Table 5. Calculations confirmed again that the Brown method application is not optimal for firefighting appliances. The use of this method has its shortcomings. The method was formulated for rail vehicles, which have high initial costs and the expected technical life is considerably longer than 10 years. For example, the rail kit RegioSprinter BR 654 costs CZK 47 million (1.85 million Euros) within the technical lifetime of 25 years. Application of this method assumes steady repair costs, as well as costs increasing with time. To evaluate the lifetime of less costly firefighting vehicles then the results are not those we expected. 
Table 3 Economic lifetime in accordance with the Expert Standard

\begin{tabular}{|c|c|c|c|c|c|c|c|c|}
\hline \multirow[b]{2}{*}{ Vehicle location } & \multirow[b]{2}{*}{$\begin{array}{l}\text { Registration } \\
\text { mark }\end{array}$} & \multicolumn{3}{|c|}{ Maintenance and repairs cost ratio $N_{u}(t)$} & \multicolumn{3}{|c|}{$\begin{array}{l}\text { Residual value of firefighting appliances in time } \\
\qquad N_{p}(t) \text { coefficients }\end{array}$} & \multirow{2}{*}{$T_{o p t}[$ year] } \\
\hline & & $A[\mathrm{CZK}]$ & $\beta[-]$ & $\begin{array}{l}\text { Correlation } \\
\text { coefficient } R\end{array}$ & $C[\mathrm{CZK}]$ & $\alpha[-]$ & $\begin{array}{l}\text { Correlation } \\
\text { coefficient } R\end{array}$ & \\
\hline Vyskov & 5B4 3485 & 7,074 & 1.2303 & 0.99 & $5,626,467$ & 0.0798 & 0.99 & 3.0 \\
\hline Pozorice & 5B4 3487 & 45,898 & 0.4209 & 1.00 & $5,626,467$ & 0.0788 & 0.99 & 6.3 \\
\hline Tisnov & 5B4 3486 & 17,721 & 0.8639 & 0.94 & $5,626,467$ & 0.0891 & 1.00 & 3.7 \\
\hline
\end{tabular}

Table 4 Input values for calculating the B-coefficient according to the Brown method

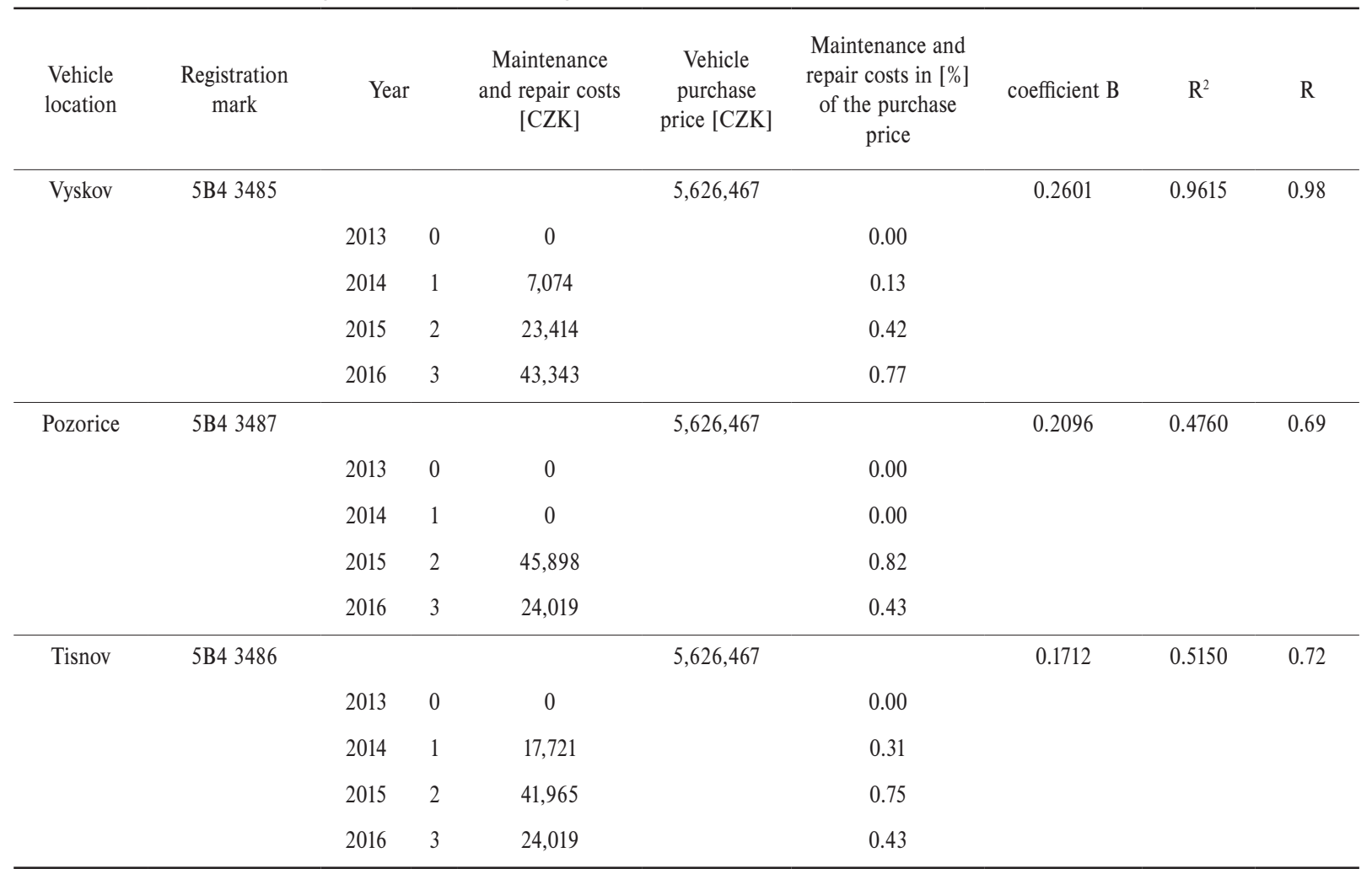

Table 5 Economic lifetime in accordance with the Brown method

\begin{tabular}{|c|c|c|c|c|}
\hline Vehicle location & Registration mark & $B[-]$ & Correlation coefficient $R$ & $T_{\text {opt }}$ [year] \\
\hline Vyskov & $5 B 43485$ & 0.2601 & 0.98 & 27.7 \\
\hline Pozorice & 5B4 3487 & 0.2096 & 0.69 & 30.9 \\
\hline Tisnov & 5B4 3486 & 0.1712 & 0.72 & 34.2 \\
\hline
\end{tabular}

Correlation coefficients of each interleaved curve for the two vehicles are very low. However, the calculated theoretical lifetime of the monitored equipment is closer to the real technical lifetime, from the economic life point of view. For example, the conception of the Czech Ministry of the Interior of 2007 [15] refers that the average age of firefighting appliance at units of the 
Fire Rescue Service of the Czech Republic exceeds 15 years and at units of the Voluntary Fire Brigades of the Czech Republic more than 29 years. However, such old vehicles have already been technologically obsolete.

\section{Conclusion}

The clear outcome resulted from the presented calculations, that the calculated optimal economic lifetime of the monitored firefighting appliances is only theoretical. The average value 4.4 years for exponential trends is out of reality. On the contrary, in accordance with the Brown method, the minimum economic lifetime of almost 28 years in the case of a vehicle deployed at the Vyskov fire station is beyond the expected technical life, which reaches maximum of 25 years for the rebuilt vehicles [15].

Compared to previous calculations for firefighting appliances based on chassis Renault Midlum [1], the average theoretical economic lifetime for exponential trend method was 6.5 years. Calculations for firefighting vehicles, based on Mercedes-Benz Atego chassis [2], showed the average theoretical economic lifetime of up to 8.0 years. Both vehicle groups were assessed for a 5-year period of operation. The longer time series resulted in the better regression functions of recorded maintenance and repair costs. For example, Brown recommends at least 8 years period for rail vehicles [10].

The next paper on the same topic, was published in the conference proceedings of the International Scientific Conference on Fire Protection, Safety and Security 2017 [16]. The firefighting appliances, based on the MAN TGM chassis, deployed at Fire Brigades of the Czech Republic in South Moravian Region were assessed in that paper. For those vehicles, the assessed period of operation was 6 years. The average theoretical lifetime from an economic point of view was 6.4 years, with using the exponential trends method. Those examples confirmed that a longer time series for evaluating maintenance and repair costs increase the economic lifetime.

\section{Acknowledgements}

This paper was supported by an internal grant of specific research "SP2014/44 - Determining aspects of operational and functional reliability of firefighting equipment."

\section{References}

[1] JANOSIK, L., JANOSIKOVA, I., POLEDNAK, P.: Assessment of Economic Life of Firefighting and Rescue Appliances Based on Chassis Renault Midlum in the Zlin Region. Communications - Scientific Letters of the University of Zilina, 18(4), 112-116, 2016.

[2] JANOSIK, L., JANOSIKOVA, I.: Determining the Lifetime Parameter of Firefighting Appliances (in Czech). 21st International Scientific Conference Solving of Critical Situations in Specific Environment, Slovakia, 239-246, 2016.

[3] JANOSIK, L.: Functional Reliability of Operation of Selected Firefighting Vehicles (in Czech). Ph.D. thesis, VSB - Technical University of Ostrava, Ostrava, p. 142, 2015.

[4] MONOSI, M., SLOBODA, A., PALUCH, B., HAJDUOVA, Z.: Fire Equipment (in Slovak). EDIS - Publishing Institution of the University of Zilina, Zilina, p. 402, 2013.

[5] JEZEK, B.: Personal Consultation and Operational Data Export from IKIS II (in Czech). Fire Rescue Service of South Moravian Region, Regional Directorate Brno, November 2016

[6] STODOLA, J.: Operational Reliability and Diagnostics (in Slovak). University of Defence, Brno, p. 88, 2002.

[7] SPACILOVA, L., JANOSIKOVA, I., HON, M.: Microeconomics B (in Czech). Workbook, $1^{\text {st }}$ ed. Faculty of Economics, VSBTechnical University of Ostrava, Ostrava, 19, p.121, 2014.

[8] JURECKA, V., JANOSIKOVA, I.: Microeconomics (in Czech). Textbook for bachelor studies, $1^{\text {st }}$ ed. Faculty of Economics, VSBTechnical University of Ostrava, Ostrava, p. 315, 2005.

[9] Instruction of the Director General of the Fire and Rescue Service and the Deputy Minister of the Interior of 13. 3. 2006 issued Machinery Order of Fire Rescue Services of the Czech Republic (in Czech). The Collection of Internal Management Director General of Fire Rescue Service of the Czech Republic and the Deputy Minister of the Interior, Prague, 9, p. 28, 2006.

[10] DANEK, A., SIROKY, J.: Theory of Replacement of Conveying Vehicles (in Czech). VSB-Technical University of Ostrava, Ostrava, p. $156,1999$.

[11] HOLUB, R., VINTR, Z.: Fundamentals of Reliability (in Czech). University of Defence, Brno, p. 174, 2002.

[12] Czech National Council Act No. 586/1992, Collection of laws, on Income Tax, as mended (in Czech). Collection of Acts, part 117, p. 48, 1992.

[13] KREJCIR, P., BRADAC, A.: Expert Standard No. I / 2005 - Valuation of Motor Vehicles (in Czech). Academic publishing CERM Ltd., Brno, p. 103, 2005. 
[14] BROWN, R. G.: Smoothing Forecasting and Prediction of Discrete Time Series. Englewood Cliffs, NJ, Prentice-Hall Inc., p. 464, 1963.

[15] Concept of Replacement of Basic Firefighting Equipment for Fire Protection Units Included to the Coverage of the Territory of the Czech Republic (in Czech). Ministry of the Interior, Directorate General of Fire Rescue Service of the Czech Republic, Prague, No.: PO -1089/IZS-2007, p. 10, 2007.

[16] JANOSIK, L., JANOSIKOVA, I., MONOSI, M.: Assessment of Economic Life of Firefighting and Rescue Appliances Based on Chassis MAN TGM in the South Moravian region. Proceedings of Fire Protection, Safety and Security 2017, Slovakia, 285-292, 2017. 